\title{
Fast-Response Liquid Crystal for Spatial Light Modulator and LiDAR Applications
}

\author{
Junyu Zou ${ }^{1}$, Qian Yang ${ }^{1}{ }^{1}$, En-Lin Hsiang ${ }^{1}$, Haruki Ooishi ${ }^{2}$, Zhuo Yang ${ }^{2}$, Kifumi Yoshidaya ${ }^{2}$ \\ and Shin-Tson $\mathrm{Wu}^{1, *(\mathbb{D})}$ \\ 1 College of Optics and Photonics, University of Central Florida, Orlando, FL 32816, USA; \\ zoujunyuwinnie@Knights.ucf.edu (J.Z.); qianyang@knights.ucf.edu (Q.Y.); \\ enlinhsiang@Knights.ucf.edu (E.-L.H.) \\ 2 DIC Corporation, Chuo City, Tokyo 103-8233, Japan; haruki-ooishi@ma.dic.co.jp (H.O.); \\ yang-zhuo@ma.dic.co.jp (Z.Y.); kifumi-yoshidaya@ma.dic.co.jp (K.Y.) \\ * Correspondence: swu@creol.ucf.edu; Tel.: +1-407-823-4763
}

\section{check for}

updates

Citation: Zou, J.; Yang, Q.; Hsiang, E.-L.; Ooishi, H.; Yang, Z.; Yoshidaya, K.; Wu, S.-T. Fast-Response Liquid Crystal for Spatial Light Modulator and LiDAR Applications. Crystals 2021, 11, 93. https://doi.org/ $10.3390 /$ cryst11020093

Received: 11 January 2021

Accepted: 22 January 2021

Published: 22 January 2021

Publisher's Note: MDPI stays neutral with regard to jurisdictional claims in published maps and institutional affiliations.

Copyright: (C) 2021 by the authors Licensee MDPI, Basel, Switzerland. This article is an open access article distributed under the terms and conditions of the Creative Commons Attribution (CC BY) license (https:// creativecommons.org/licenses/by/ $4.0 /$ )

\begin{abstract}
We report a new nematic mixture for liquid-crystal-on-silicon spatial light modulator (SLM) and light detection and ranging (LiDAR) applications. The mixture exhibits a relatively high birefringence $(\Delta n)$, moderate dielectric anisotropy $(\Delta \varepsilon)$, low viscosity, and reasonably good photostability. To achieve $2 \pi$ phase change at $5 \mathrm{~V}$, the response time (on + off) is $2.5 \mathrm{~ms}$ at $40{ }^{\circ} \mathrm{C}$ with $\lambda=633 \mathrm{~nm}$, and $5.9 \mathrm{~ms}$ with $\lambda=905 \mathrm{~nm}$. After exposure by a blue laser $(\lambda=465 \mathrm{~nm})$ with a total dosage up to $20 \mathrm{MJ} / \mathrm{cm}^{2}$, this mixture shows no sign of photodegradation. Widespread applications of this material for high brightness SLMs, LiDAR, near-eye displays, and head-up displays are foreseeable.
\end{abstract}

Keywords: liquid crystals; spatial light modulator; liquid-crystal-on-silicon; photostability

\section{Introduction}

Liquid crystals (LCs) have been widely used in display devices [1,2], such as smartphones, computers, TVs, emergent augmented reality (AR) and virtual reality (VR) [3], and vehicle displays [4], to name a few. For these amplitude modulations, to achieve high contrast ratio, the pixelated liquid crystal display (LCD) panel is sandwiched between two crossed polarizers, and each pixel is addressed by a thin-film transistor independently. For example, an $8 \mathrm{~K}$ full-color LCD $(7680 \times 4320 \times 3)$ consists of 99.532 million sub-pixels. In addition to intensity modulators, LC can also work as a phase-only spatial light modulator (SLM). Under such a circumstance, no polarizer is needed if the incident laser is already linearly polarized. Both transmission-type [5] and reflection-type SLMs [6] have been developed. The former has a simpler optical system, but its shortcomings are: (1) limited aperture ratio, especially as the pixel density increases, and (2) slower response time. On the reflection-type SLM, liquid-crystal-on-silicon (LCOS) [6-8] is a well-developed technology because of its high-resolution density, low operation voltage, and fast response time. The LCoS based SLMs have also found many useful applications, such as multi-focus AR display $[9,10]$ and head-up display [4] to overcome the vergence-accommodation conflict issue, beam shaping for lithography [11], adaptive optics for wavefront correction [12], wavelength selective switch for telecommunications [13], and non-mechanical beam steering for light detection and ranging (LiDAR) for advanced driver-assistance systems (ADAS) and future self-driving vehicles [14]. Recently, a liquid crystal integrated metasurface was applied to steer a laser beam for LiDAR [15]. For this kind of SLM, response time is a key factor. To achieve the desired $240 \mathrm{~Hz}$ frame rate, the $2 \pi$ phase-change response time should be less than $4 \mathrm{~ms}$. However, several demonstrated prototypes can only operate at $60 \mathrm{~Hz}$, including the head mounted displays from Microsoft [16] and Oculus [17]. Therefore, there is an urgent need to develop fast-response LC materials with low operation voltage $\left(V_{2 \pi}=5 V_{r m s}\right)$ for LCoS SLMs. 
In a reflective LCoS SLM, the phase change $\delta=2[2 \pi d \Delta n / \lambda]$, here the first factor 2 represents the double pass of the incident beam, $d$ is the LC layer thickness (i.e., cell gap), $\Delta n$ is the LC birefringence, and $\lambda$ is the wavelength. Reducing the cell gap is a straightforward way to achieve fast response time, which is proportional to $\mathrm{d}^{2}$. Increasing the operating temperature helps greatly to lower the rotational viscosity, which in turn reducing the response time. Two thermal effects from the driving circuits of CMOS (complementary metal-oxide-semiconductor) backplane and the high-power light source contribute to increasing the operating temperature of an $\mathrm{LCoS}$ to $40-50{ }^{\circ} \mathrm{C}$ [18]. As the temperature increases, both birefringence and viscoelastic constant decrease but at different rates [19]. The decreased birefringence demands either a thicker cell gap or a higher birefringence LC at the room temperature, while lower viscoelastic constant helps to achieve faster response time. In the meantime, extending the SLM lifetime is also essential, which is jointly determined by the photostability of the employed alignment layer (organic polyimide or inorganic $\mathrm{SiO}_{x}$ ) and LC material [20,21]. The light source commonly used in an LCoS projector is a high-power arc lamp, RGB LEDs (red, green, and blue light-emitting diodes), or lasers. Among the RGB light sources, the high energy blue photons are most harmful and may cause gradual device degradation, depending on the LC material employed. The inorganic $\mathrm{SiO}_{x}$ alignment layer [22] has been proven to withstand long-term UV or blue light exposure [23], but high $\Delta n$ LC materials with excellent photostability in the blue spectral region still have not been investigated thoroughly.

In this paper, we present a new LC mixture formulated by DIC, designated as A4907, for LCoS SLM and LiDAR applications. Its response time is $\sim 2.5 \mathrm{~ms}$ at $\lambda=633 \mathrm{~nm}$ and $40{ }^{\circ} \mathrm{C}$ and $\sim 5.9 \mathrm{~ms}$ at $\lambda=905 \mathrm{~nm}$. Such a fast response time results from the relatively high birefringence and low viscoelastic constant of A4907. Moreover, this mixture exhibits a reasonably good photostability at $\lambda=465 \mathrm{~nm}$ for a dosage up to $20 \mathrm{MJ} / \mathrm{cm}^{2}$.

\section{Material Characterizations}

The physical properties of A4907 are listed in Table 1. For comparison, we also show the physical properties of Merck TL-216 and UCF-216 [24]. The melting temperature $\left(T_{m}\right)$ and clearing temperature $\left(T_{\mathcal{c}}\right)$ were measured by differential scanning calorimetry (DSC, TA Instruments Q100, Lukens Drive, New Castle, DE 19720). All these three materials have a wide nematic range that satisfies the requirement for most LCoS applications. The dielectric constants were measured with a multifrequency LCR meter, HP-4274 (Santa Rosa, CA, United States). The viscoelastic constant $\gamma_{1} / K_{11}$ of each mixture was measured from the free relaxation response time of a test cell [25]. From Table 1, we can see that A4907 has higher birefringence and lower viscoelastic constant than the other two mixtures, which implies it can achieve a faster response time.

Table 1. Measured physical properties of DIC A4907, MerckTL-216 and UCF-216 at $T=22{ }^{\circ} \mathrm{C}$.

\begin{tabular}{cccc}
\hline LC Mixture & A4907 & TL-216 & UCF-216 \\
\hline$T_{\mathcal{C}}\left({ }^{\circ} \mathrm{C}\right)$ & 91.9 & 80.0 & 81.8 \\
$T_{m}\left({ }^{\circ} \mathrm{C}\right)$ & -19 & -20 & -20 \\
$\Delta n @ 633 \mathrm{~nm}$ & 0.220 & 0.205 & 0.215 \\
$\Delta \varepsilon @ 1 \mathrm{kHz}$ & 7.3 & 5.5 & 7.6 \\
$\varepsilon \perp @ 1 \mathrm{kHz}$ & 3.8 & 4.2 & 4.2 \\
$K_{11}(\mathrm{pN})$ & 13.3 & 14.4 & 14.6 \\
$K_{33}(\mathrm{pN})$ & 16.3 & 19.6 & - \\
$\gamma_{1} / K_{11}\left(\mathrm{~ms} / \mu \mathrm{m}^{2}\right)$ & 12.9 & 19.0 & 14.5 \\
\hline
\end{tabular}

\subsection{Birefringence}

To measure $\Delta n$, the LC mixture was filled into a homogeneous cell, whose cell gap $\mathrm{d}=5.34 \mu \mathrm{m}$, and the pretilt angle of the rubbed polyimide alignment layers is about $3^{\circ}$. This cell was sandwiched between two crossed polarizers and activated with a $1 \mathrm{kHz}$ square-wave AC voltage. A Linkam heating stage was applied to control the sample 
temperature through a temperature programmer TMS94 (Linkam Scientific Instruments Ltd., Waterfield, Epsom, Tadworth KT20 5LR, UK). The birefringence at corresponding temperature was calculated from the measured phase retardation. Figure 1 describes the measured (dots) and fitting (solid line) results of birefringence at different temperatures with a working wavelength $\lambda=633 \mathrm{~nm}$ (He-Ne laser). The fitting curve is produced from following equation [26]:

$$
\Delta n=\Delta n_{0} S=\Delta n_{0}\left(1-T / T_{\mathcal{c}}\right)^{\beta}
$$

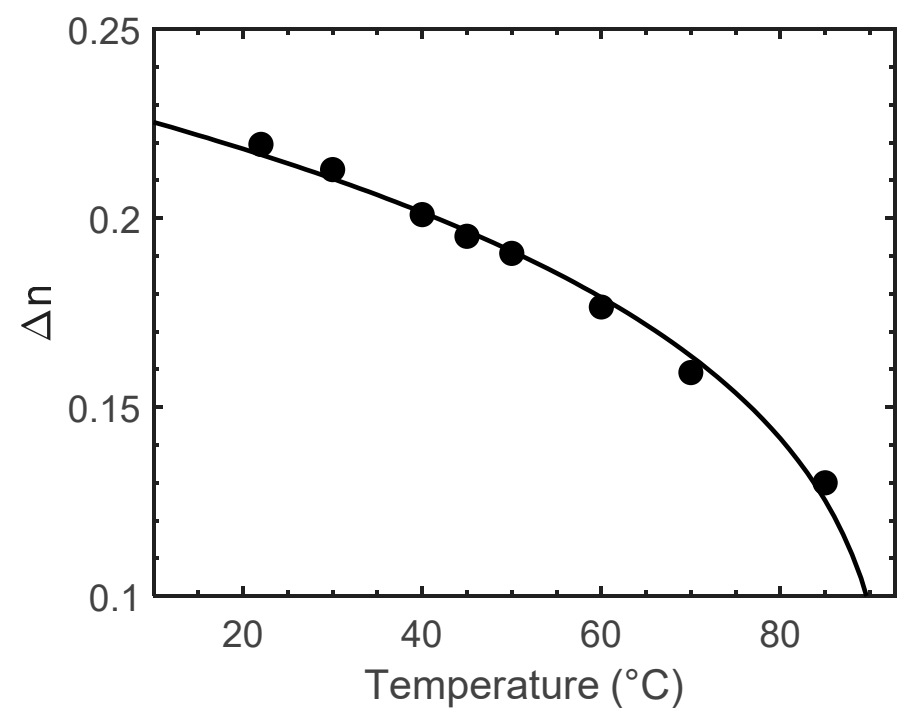

Figure 1. Temperature-dependent birefringence of A4907 at $\lambda=633 \mathrm{~nm}$ and $1 \mathrm{kHz}$. Dots are measured data and solid line is fitting curve with Equation (1).

In Equation (1), $\Delta n_{0}$ represents the extrapolated birefringence at $T=0 \mathrm{~K}, S$ is the order parameter, $T_{\mathcal{C}}$ (unit: $\mathrm{K}$ ) is the clearing point temperature of the $\mathrm{LC}$, which is measured by DSC, and exponent $\beta$ is a material parameter. By fitting the experimental data with Equation (1), both $\Delta n_{0}$ and $\beta$ can be obtained. The results are listed in Table 2 . For convenience, we use Celsius $\left({ }^{\circ} \mathrm{C}\right.$ ) instead of Kelvin temperature $(\mathrm{K})$ in the following figures.

Table 2. Fitting parameters obtained through Equations (1)-(3).

\begin{tabular}{ccccccc}
\hline $\begin{array}{c}\text { LC } \\
\text { Mixture }\end{array}$ & $\Delta n_{\mathbf{0}}$ & $\boldsymbol{\beta}$ & $\begin{array}{c}G @ 4 \mathbf{0}^{\circ} \mathrm{C} \\
\left(\mu \mathbf{m}^{-2}\right)\end{array}$ & $\begin{array}{c}\lambda^{*} @ 40^{\circ} \mathrm{C} \\
(\boldsymbol{\mu m})\end{array}$ & $\begin{array}{c}A \\
\left(\mathbf{m s} / \mu \mathbf{m}^{2}\right)\end{array}$ & $\begin{array}{c}E_{a} \\
(\mathbf{m e V})\end{array}$ \\
\hline $\mathrm{A} 4907$ & 0.326 & 0.249 & 3.06 & 0.237 & $6.19 \times 10^{-6}$ & 358 \\
\hline
\end{tabular}

The wavelength dispersion of A4907 is also investigated. For a working LCoS device, the operating temperature is about $40-50{ }^{\circ} \mathrm{C}$ because of the thermal effect from the CMOS backplane and illumination light. Therefore, we measured the wavelength dispersion at 40 ${ }^{\circ} \mathrm{C}$ to investigate the electro-optical performances at RGB colors. In experiment, He- $\mathrm{Ne}$ laser $(\lambda=632.8 \mathrm{~nm})$ and a tunable Argon ion laser $(\lambda=457 \mathrm{~nm}, 488 \mathrm{~nm}$, and $514 \mathrm{~nm})$ were used as probing light sources. The obtained results are shown in Figure 2, where dots indicate measured data and solid line is the fitting curve using the single-band birefringence dispersion equation, which works for LC mixtures [27]:

$$
\Delta n=G \frac{\lambda^{2} \lambda^{* 2}}{\lambda^{2}-\lambda^{* 2}} .
$$




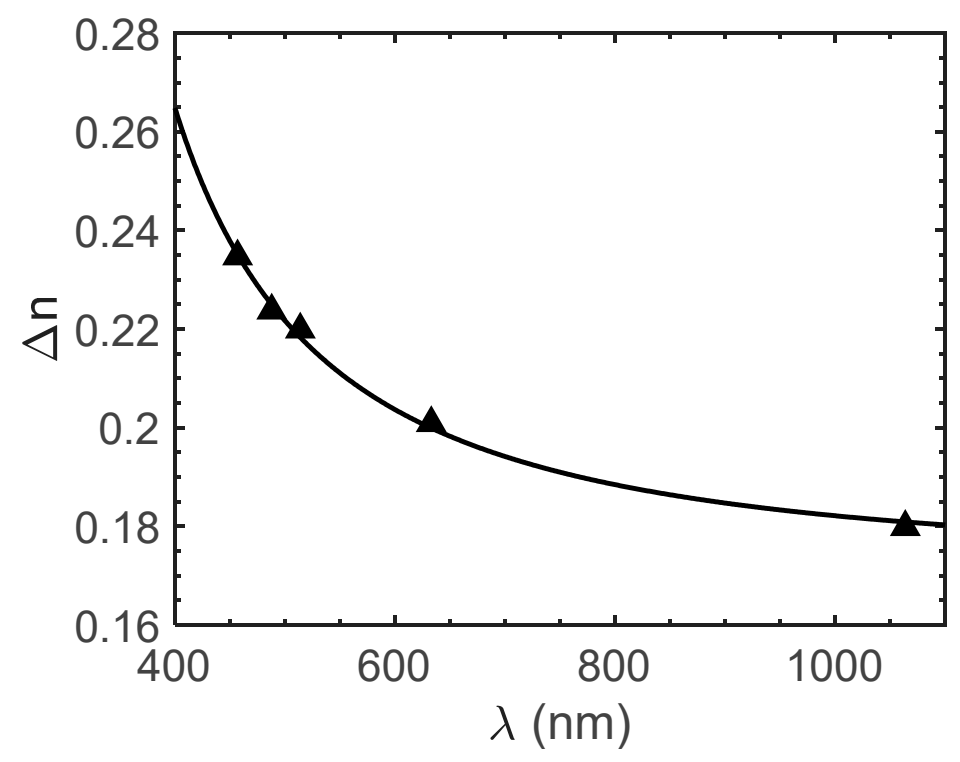

Figure 2. Wavelength-dependent birefringence of A4907 at $40^{\circ} \mathrm{C}$ and $1 \mathrm{kHz}$. Triangles are measured data and solid line is fitting curve with Equation (2).

In Equation (2), $G$ is the proportionality constant and $\lambda^{*}$ is the mean resonance wavelength. Both $G$ and $\lambda^{*}$ can be obtained by fitting experimental data with Equation (2) and results are listed in Table 2. At $40{ }^{\circ} \mathrm{C}$, the $\Delta n$ of A4907 is 0.200 at $\lambda=633 \mathrm{~nm}$ but slightly decreases to 0.185 at $\lambda=905 \mathrm{~nm}$.

\subsection{Viscoelastic Constant}

The viscoelastic constant $\gamma_{1} / K_{11}$ is also temperature dependent. We obtain this value from the measured transient decay time of the LC cell. The experimental (squares) and fitting (solid line) results are shown in Figure 3. The fitting curve is plotted from following equation [19]:

$$
\frac{\gamma_{1}}{K_{11}}=A \frac{\exp \left(E_{a} / k_{B} T\right)}{\left(1-T / T_{\mathcal{c}}\right)^{\beta}}
$$

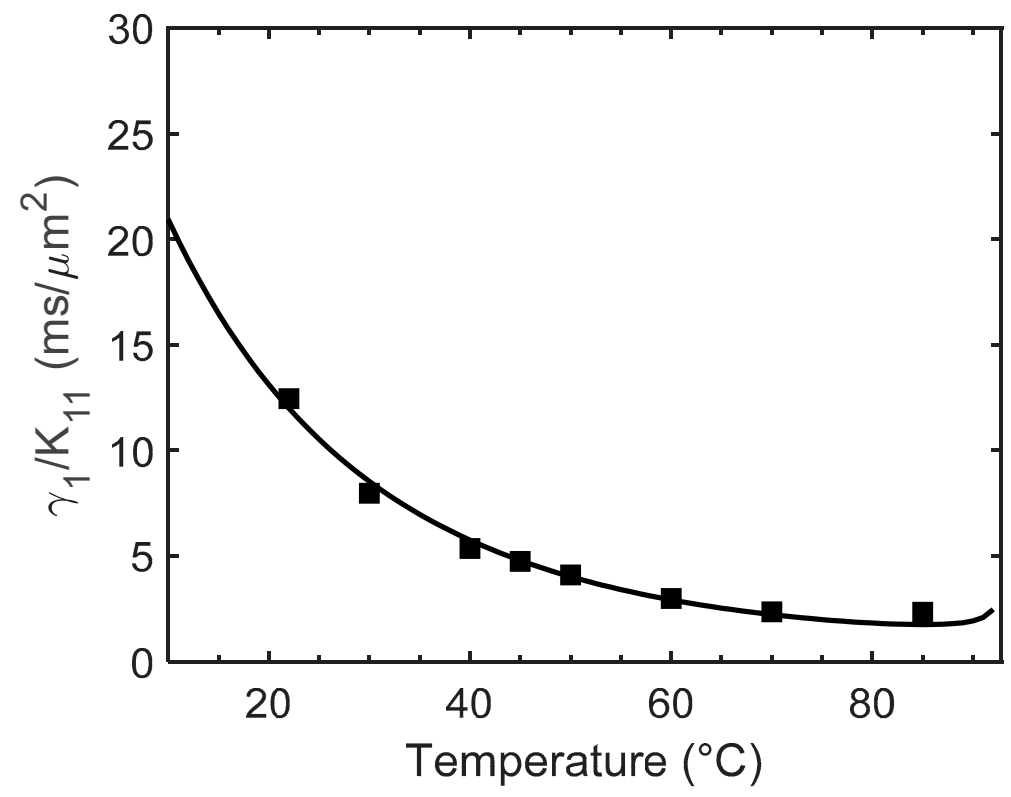

Figure 3. Temperature-dependent viscoelastic constant of DIC A4907. Squares are measured data and solid line is fitting curve with Equation (3). 
In Equation (3), $k_{B}$ is the Boltzmann constant, $E_{a}$ is the activation energy, and $A$ is the proportionality constant, whose values are also included in Table 2.

\subsection{Figure of Merit}

Figure of merit, defined as FoM $=\Delta n^{2} /\left(\gamma_{1} / K_{11}\right)$, is a fair way to compare the electro-optic performance of different materials [19]. Results are plotted in Figure 4, where the dots are experimental data and the solid line is the fitting curve. As the temperature increases, FoM increases first, reaching a peak, and then declines sharply as the temperature approaches $T_{c}$. Detailed mechanisms have been explained in [19]. In brief, as the temperature increases, both $\Delta n$ and $\gamma_{1} / K_{11}$ decrease but at different rates. In the beginning, $\Delta n$ decreases more slowly than $\gamma_{1} / K_{11}$, leading to an increased FoM. As the temperature approaches $T_{c}, \Delta n$ decreases more rapidly than $\gamma_{1} / K_{11}$, resulting in a sharply declined FoM. The optimal operating temperature where FoM has a maximum value usually occurs at $\sim 20{ }^{\circ} \mathrm{C}$ below $T_{C}$. From Figure 4, operating A4907 at $40{ }^{\circ} \mathrm{C}$ enhances the FoM by nearly $2 \mathrm{X}$ than that at $22{ }^{\circ} \mathrm{C}$.

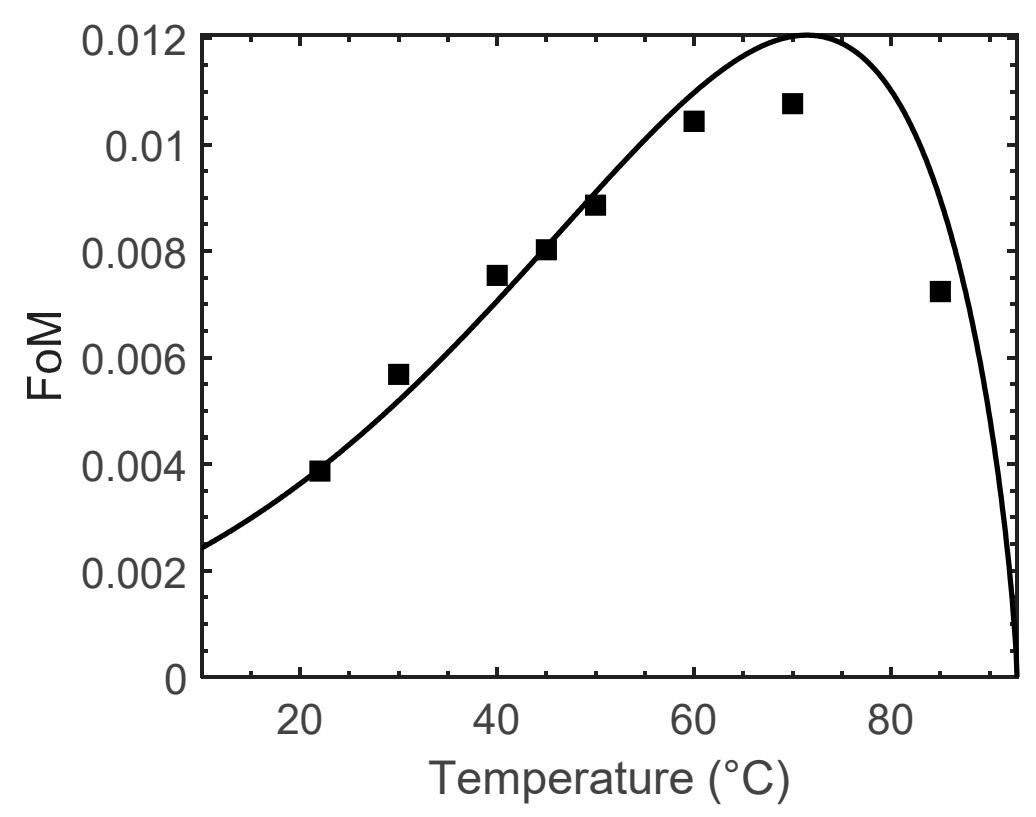

Figure 4. Temperature-dependent FoM of DIC A4907. Squares are measured data and solid line is fitting curve.

\subsection{Voltage Dependent Phase Change}

As mentioned before, the operating temperature of a working LCoS device is about 40-50 ${ }^{\circ} \mathrm{C}$. Therefore, our studies focus on two temperatures: $40{ }^{\circ} \mathrm{C}$ and $50{ }^{\circ} \mathrm{C}$. In experiment, the voltage-dependent transmittance (V-T) curve of A4907 was measured at $\lambda=633 \mathrm{~nm}$, then it was converted to the voltage-dependent phase $(V-\Phi)$ curve depicted in Figure 5. We should mention here that our measurement is based on transmission-type cells, but the results can be converted to the corresponding reflection-type cells easily. According to Figure 5, the $V_{2 \pi}$ of A4907 is $2.6 V_{r m s}$ at $40{ }^{\circ} \mathrm{C}$ and $2.7 V_{r m s}$ at $50{ }^{\circ} \mathrm{C}$ (red lines). The reason that $V_{2 \pi}$ slightly increases is mainly attributed to the decreased birefringence as the temperature increases. Since our allowed $V_{2 \pi}$ is $5 V_{r m s}$, we could use a thinner cell gap to achieve the desired $2 \pi$ phase change. However, the cell gap in our lab is limited, but we can extrapolate the $V-\Phi$ curve of a different cell gap by using the phase retardation equation $\delta=2 \pi d \Delta n / \lambda$. For example, if the operating temperature is $50{ }^{\circ} \mathrm{C}$, then a thinner cell gap ( $3.95 \mu \mathrm{m}$ transmissive cell or $1.98 \mu \mathrm{m}$ reflective LCoS) can be applied to make $V_{2 \pi}$ at $5 V_{r m s}$, as the blue line shows. In the meantime, the response time will be faster, which will be discussed quantitatively later. 

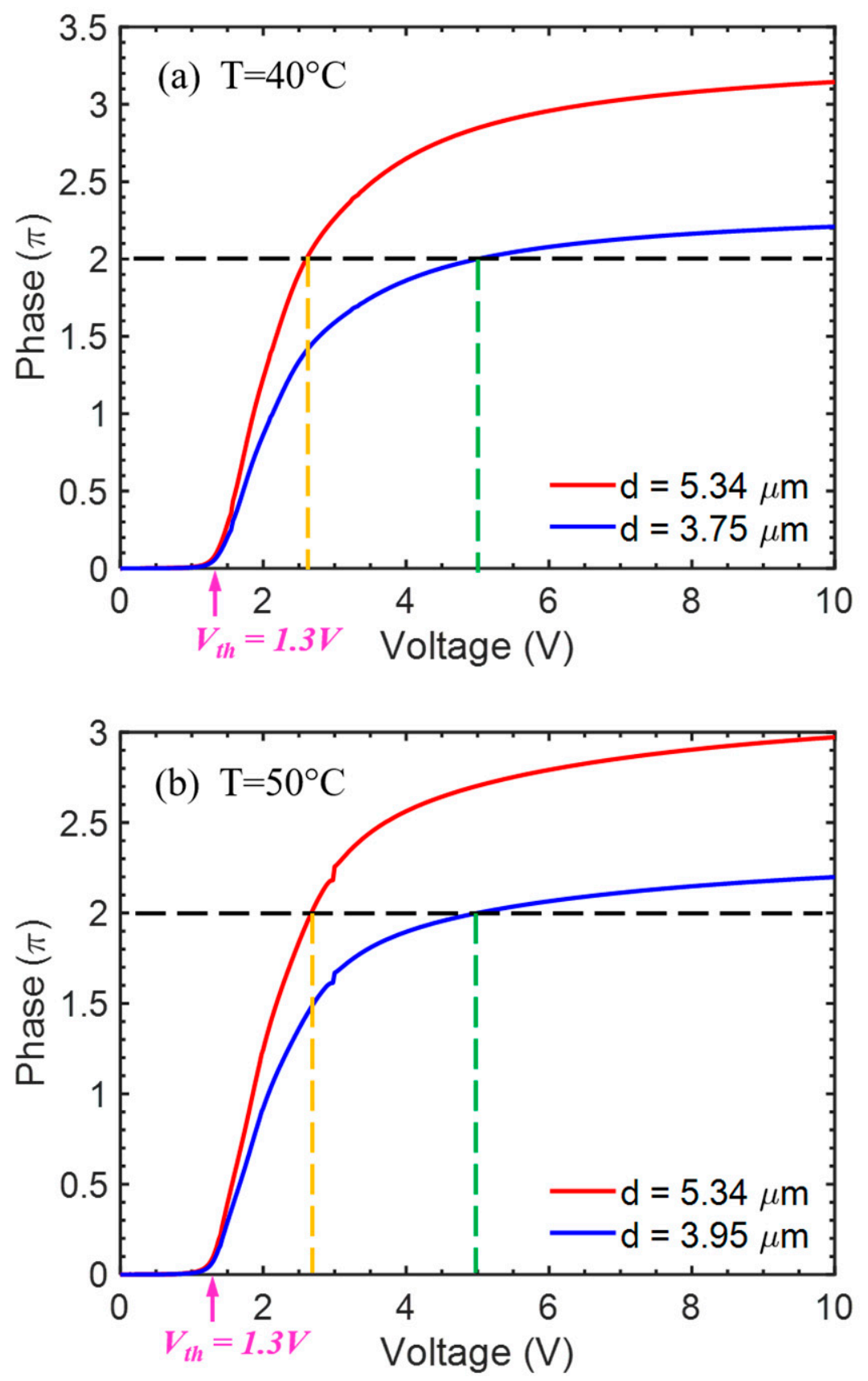

Figure 5. Measured (red line) voltage-dependent phase change of a transmissive A4907 test cell at $\lambda=633 \mathrm{~nm}$ and $1 \mathrm{kHz}$. Cell gap is $d=5.34 \mu \mathrm{m}$, with $V_{2 \pi}=2.6 V_{r m s}$ at $T=40{ }^{\circ} \mathrm{C}$ in (a) and $V_{2 \pi}=2.7 V_{r m s}$ at $T=50{ }^{\circ} \mathrm{C}$ in (b). If we operate $\mathrm{A} 4907$ at $50{ }^{\circ} \mathrm{C}$, we could use a slightly thinner cell gap $(3.95 \mu \mathrm{m}$ transmissive cell or $1.98 \mu \mathrm{m}$ reflective LCoS, blue line in $(\mathbf{b}))$ to increase $V_{2 \pi}$ to $5 V_{\text {rms }}$.

Similar to $\lambda=633 \mathrm{~nm}$, we can also study the $V-\Phi$ curve of this material at $\lambda=905 \mathrm{~nm}$, which is the typical working wavelength for LIDAR. Based on the measured $V-\Phi$ curve at $\lambda=633 \mathrm{~nm}$, we can convert it to a desired wavelength using the phase retardation equation $\delta=2 \pi d \Delta n / \lambda$. According to the fitting results in Figure 2, we find the birefringence of A4907 is 0.200 at $\lambda=633 \mathrm{~nm}$ and 0.185 at $\lambda=905 \mathrm{~nm}$. Thus, it is quite straightforward to convert the $V-\Phi$ curve from $\lambda=633 \mathrm{~nm}$ (red solid line) to that at $\lambda=905 \mathrm{~nm}$, as the red dashed lines show in Figure 6. However, after conversion the phase change is slightly less than $2 \pi$ at $5 \mathrm{~V}$. Therefore, we slightly increase the cell gap from $5.34 \mu \mathrm{m}$ to $5.81 \mu \mathrm{m}$ to boost the phase change to $2 \pi$ at $5 \mathrm{~V}$. The results are plotted in Figure 6 as the blue dashed lines. 


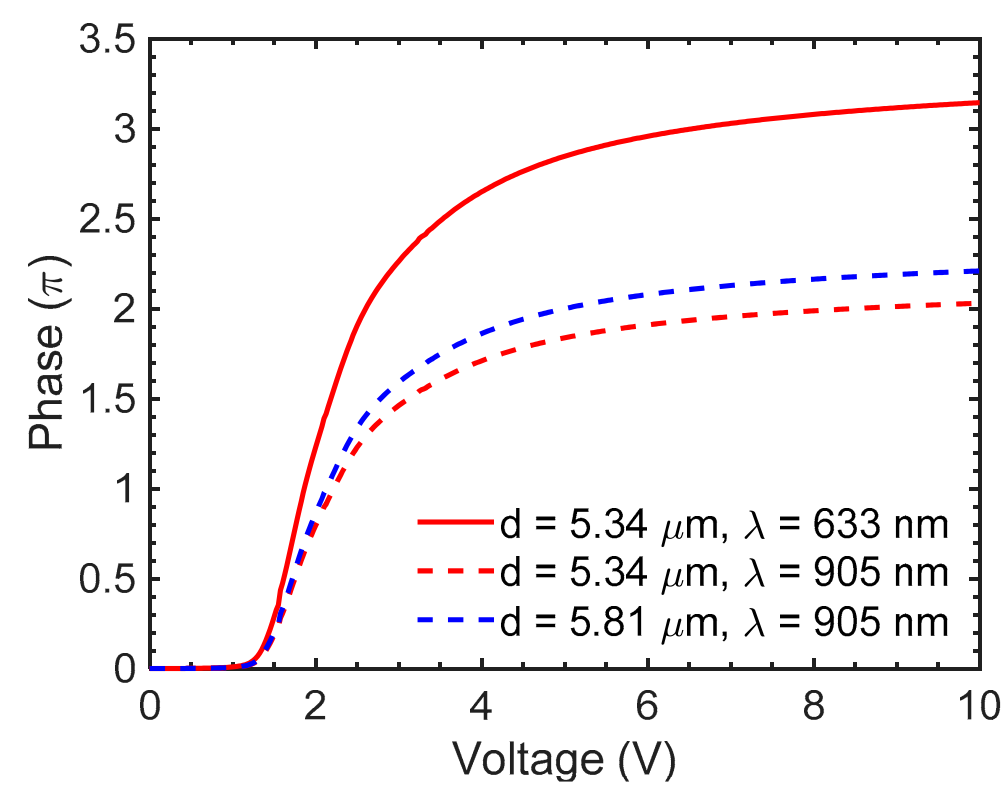

Figure 6. Voltage-dependent phase change of a transmissive A4907 test cell at $\lambda=633 \mathrm{~nm}$ (red solid line, measured) and $\lambda=905 \mathrm{~nm}$ (red dashed line, converted). Cell gap is $d=5.34 \mu \mathrm{m}$ at $T=40{ }^{\circ} \mathrm{C}$. To obtain $V_{2 \pi}=5 V_{r m s}$, we should increase the cell gap from $5.34 \mu \mathrm{m}$ to $5.81 \mu \mathrm{m}$ (blue dashed lines).

\subsection{Response Time}

The switching time (rise time and decay time) of an LC phase modulator between two gray levels $\left(V_{1}\right.$ and $\left.V_{2}\right)$ are determined by the LC cell gap, viscoelastic constant, threshold voltage and operating voltages as follows [28]:

$$
\begin{gathered}
\tau_{o n}=\frac{\tau_{0}}{\left(V_{2} / V_{t h}\right)^{2}-1}, \\
\tau_{o f f}=\frac{\tau_{0}}{\left|\left(V_{1} / V_{t h}\right)^{2}-1\right|}, \\
\tau_{0}=\frac{\gamma_{1} d^{2}}{K_{11} \pi^{2}} .
\end{gathered}
$$

In Equations (4)-(6), $V_{\text {th }}$ is the threshold voltage, $\tau_{0}$ is the free relaxation time, $V_{1}$ and $V_{2}$ are the low and high gray-level voltage, respectively. According to previous investigations [28,29], the sum of free relaxation time $\left(V_{1}=0\right)$ and turn-on time $\left(V_{2}=8\right.$ th gray level) is about the same as the average gray-to-gray rise and decay time. Therefore, we let $V_{1}=0$ and $V_{2}=V_{2 \pi}$ in the response time extrapolation later.

We measured the rise time and decay time of A4907 at $T=40^{\circ} \mathrm{C}$ and $50{ }^{\circ} \mathrm{C}$ with $2 \pi$ phase change voltage. Then the experimental data are converted to reflection-type cells. Results are shown in Table 3. Since the cell gap of the converted reflection-type cell is only one half of the transmissive one, its response time is $4 x$ faster than that of the corresponding transmissive cell. For a $d=5.34 \mu \mathrm{m}$ transmission-type cell at $\lambda=633 \mathrm{~nm}$, the total response time $\left(\tau_{\text {on }}+\tau_{\text {off }}\right)$ is $8.25 \mathrm{~ms}$ at $T=40^{\circ} \mathrm{C}$, and $6.23 \mathrm{~ms}$ at $50{ }^{\circ} \mathrm{C}$. Since the allowed $V_{2 \pi}$ is $5 V_{r m s}$, a thinner cell gap can be adopted, as mentioned above (blue lines in Figure 5). Under such condition, the value of $V_{2 \pi}$ increases, which significantly reduces the rise time, as Equation (4) indicates. For a $1.88 \mu \mathrm{m}$ reflection-type cell, the extrapolated total response time is $2.5 \mathrm{~ms}$ at $T=40^{\circ} \mathrm{C}$. If the operation temperature is increased to $50{ }^{\circ} \mathrm{C}$, the total response time is further reduced to $2.20 \mathrm{~ms}$ by using a $1.98 \mu \mathrm{m}$ cell gap in reflective mode, which enables an LCoS SLM to operate at $400 \mathrm{~Hz}$. Furthermore, if the working wavelength shifts to $905 \mathrm{~nm}$ for LIDAR applications at $T=40^{\circ} \mathrm{C}$, then the corresponding cell gap should 
increase to $2.91 \mu \mathrm{m}$ for reflective mode, so that $V_{2 \pi}$ is $5 V_{r m \mathrm{~s}}$. In this case, the total response time is $5.9 \mathrm{~ms}$.

Table 3. Measured response time of a transmissive A4907 with $d=5.34 \mu \mathrm{m}$, and the extrapolated response time to the corresponding reflective cells at $40^{\circ} \mathrm{C}(\lambda=633 \mathrm{~nm}$ and $\lambda=905 \mathrm{~nm})$ and $50{ }^{\circ} \mathrm{C}(\lambda=633 \mathrm{~nm})$.

\begin{tabular}{|c|c|c|c|c|c|c|c|c|}
\hline$T\left({ }^{\circ} \mathrm{C}\right)$ & $\lambda(\mathrm{nm})$ & $d(\mu \mathrm{m})$ & $V_{t h}(\mathrm{~V})$ & $V_{2 \pi}(\mathrm{V})$ & $\tau_{o n}(\mathrm{~ms})$ & $\tau_{o f f}(\mathrm{~ms})$ & $\begin{array}{c}\tau_{\text {total }}(\mathrm{ms}) \\
\text { Transmissive }\end{array}$ & $\begin{array}{l}\tau_{\text {total }}(\mathrm{ms}) \\
\text { Reflective }\end{array}$ \\
\hline 40 & 633 & 5.34 & 1.3 & 2.6 & 16.6 & 16.4 & 33.0 & 8.3 \\
\hline 40 & 633 & 3.75 & 1.3 & 5.0 & 1.8 & 8.1 & 10.0 & 2.5 \\
\hline 40 & 905 & 5.81 & 1.3 & 5.0 & 4.3 & 19.4 & 23.6 & 5.9 \\
\hline 50 & 633 & 5.34 & 1.3 & 2.7 & 11.6 & 13.3 & 24.9 & 6.2 \\
\hline 50 & 633 & 3.95 & 1.3 & 5.0 & 1.5 & 7.3 & 8.8 & 2.2 \\
\hline
\end{tabular}

\subsection{Photostability}

For LCoS projection displays, the employed light source could be a high-power arc lamp, RGB LEDs, or lasers. Although only RGB wavelengths are considered, the device lifetime could still be affected by the blue light, depending on the employed organic or inorganic alignment layer and the LC compound structures. For high brightness displays, inorganic $\mathrm{SiO}_{x}$ alignment layers [22] have been proven to be robust after long-term UV or blue light exposure [23], but high $\Delta n$ LC materials with excellent photostability in the blue spectral region still have not been investigated thoroughly.

To study the photostability of A4907, we filled the LC mixture in a $9.42 \mu \mathrm{m}$ test cell. This test cell is comprised of ITO (indium tin oxide)-glass substrates overcoated with an inorganic $\mathrm{SiO}_{x}$ alignment layer. Then, the filled test cell was exposed to a high-power $\mathrm{CW}$ laser with $\lambda=465 \mathrm{~nm}$ and intensity of $72 \mathrm{~W} / \mathrm{cm}^{2}$. We checked the birefringence and viscoelastic constant of the sample every $24 \mathrm{~h}$. The measured results are recorded in Figure 7. As the dosage increases, $\Delta n$ and $\gamma_{1} / K_{11}$ remain basically unchanged in the first $20 \mathrm{MJ} / \mathrm{cm}^{2}$. To rule out the damage from $\mathrm{SiO}_{x}$ alignment layer and ITO, we measured the photostability of an empty cell without LC. Results indicate that the empty cell can survive over $500 \mathrm{MJ} / \mathrm{cm}^{2}$ dosage by the same high-power $\mathrm{CW}$ laser.

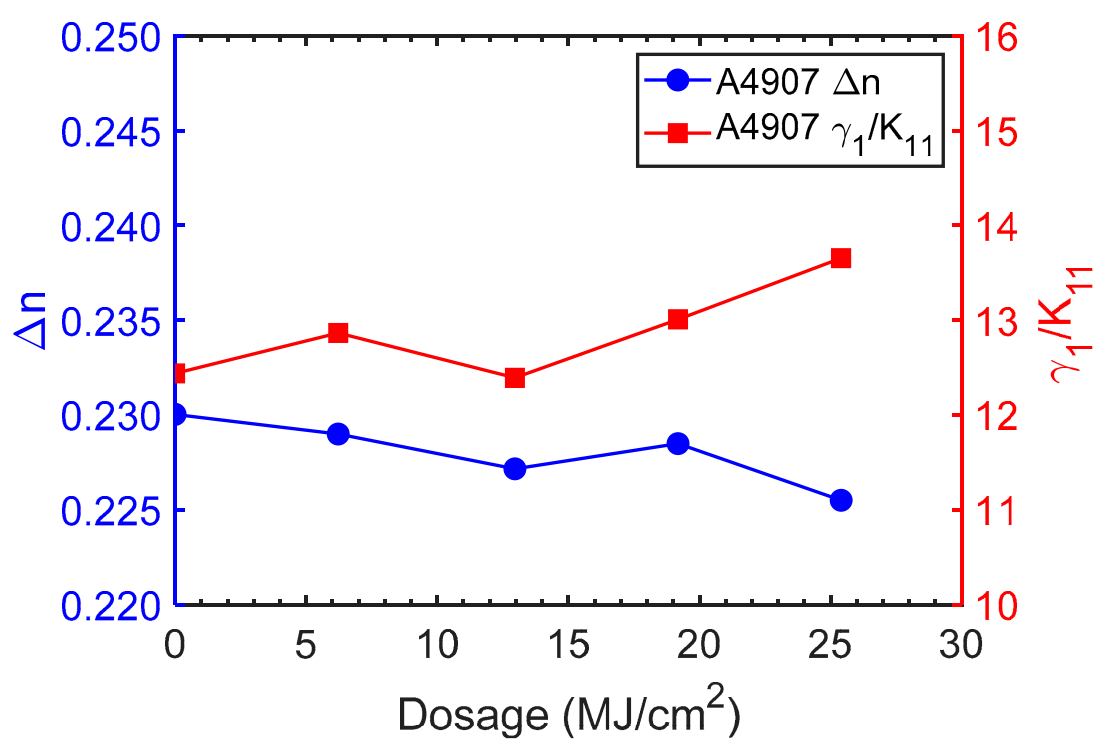

Figure 7. Measured photostability of A4907 with a blue laser at $\lambda=465 \mathrm{~nm}$ at $22{ }^{\circ} \mathrm{C}$. Probing laser $\lambda=633 \mathrm{~nm}$. 


\section{Conclusions}

In conclusion, a new LC mixture, designated as A4907, was developed. This mixture is a promising candidate for high brightness LCoS SLM and LIDAR applications. A4907 exhibits fast response time, low operation voltage, and adequate photostability. It achieves $2.5 \mathrm{~ms}$ total response time at $40^{\circ} \mathrm{C}$ for $\lambda=633 \mathrm{~nm}$, and $5.9 \mathrm{~ms}$ for $\lambda=905 \mathrm{~nm}$, respectively, while the $2 \pi$ phase change voltage remains as low as $5 V_{r m s}$. No sign of photodegradation up to $20 \mathrm{MJ} / \mathrm{cm}^{2}$ dosage is observed at $\lambda=465 \mathrm{~nm}$. Practical applications of A4907 for laserbased SLMs, LiDAR, high brightness AR displays, and head-up displays are foreseeable.

Author Contributions: Methodology, J.Z., Q.Y., and E.-L.H.; Material optimization, H.O., Z.Y., K.Y.; writing —original draft preparation, J.Z.; writing—review and editing, S.-T.W.; supervision, S.-T.W. All authors have read and agreed to the published version of the manuscript.

Funding: Sony Corporation.

Institutional Review Board Statement: Not applicable.

Informed Consent Statement: Not applicable.

Data Availability Statement: Not applicable.

Acknowledgments: The UCF group is indebted to Sony Corp. for the financial support, and Akiko Toriyama and Koichi Nagasawa for useful discussion.

Conflicts of Interest: The authors declare no conflict of interest.

\section{References}

1. Schadt, M. Milestone in the history of field-effect liquid crystal displays and materials. Jpn. J. Appl. Phys. 2009, 48, 03B001. [CrossRef]

2. Huang, Y.; Hsiang, E.L.; Deng, M.Y.; Wu, S.T. Mini-LED, micro-LED and OLED displays: Present status and future perspectives. Light Sci. Appl. 2020, 9, 105. [CrossRef]

3. Zhan, T.; Yin, K.; Xiong, J.; He, Z.; Wu, S.T. Augmented reality and virtual reality: Perspectives and challenges. iScience 2020, 23, 101397. [CrossRef]

4. Zhan, T.; Lee, Y.H.; Tan, G.; Xiong, J.; Yin, K.; Gou, F.; Zou, J.; Zhang, N.; Zhao, D.; Yang, J.; et al. Pancharatnam-Berry optical elements for head-up and near-eye displays. J. Opt. Soc. Am. B 2019, 36, D52-D65. [CrossRef]

5. McManamon, P.F.; Dorschner, T.A.; Corkum, D.L.; Friedman, L.J.; Hobbs, D.S.; Holz, M.; Liberman, S.; Nguyen, H.Q.; Resler, D.P.; Sharp, R.C.; et al. Optical phased array technology. Proc. IEEE 1996, 84, 268-298. [CrossRef]

6. Cuypers, D.; de Smet, H.; van Calster, A. VAN LCOS microdisplays: A decade of technological evolution. J. Disp. Technol. 2011, 7, 127-134. [CrossRef]

7. Zhang, Z.; You, Z.; Chu, D. Fundamentals of phase-only liquid crystal on silicon (LCOS) devices. Light Sci. Appl. 2014, 3, e216. [CrossRef]

8. Chen, H.M.; Yang, J.P.; Yen, H.T.; Hsu, Z.N.; Huang, Y.; Wu, S.T. Pursuing high quality phase-only liquid crystal on silicon (LCoS) devices. Appl. Sci. 2018, 8, 2323. [CrossRef]

9. Zhan, T.; Xiong, J.; Zou, J.; Wu, S.T. Multifocal displays: Review and prospect. PhotoniX 2020, 1, 10. [CrossRef]

10. Hua, H. Enabling focus cues in head-mounted displays. Proc. IEEE 2017, 105, 805-824. [CrossRef]

11. Bahk, S.W.; Fess, E.; Kruschwitz, B.E.; Zuegel, J.D. A high-resolution, adaptive beam-shaping system for high-power lasers. Opt. Express 2010, 18, 9151-9163. [CrossRef] [PubMed]

12. Hu, L.; Xuan, L.; Liu, Y.; Cao, Z.; Li, D.; Mu, Q. Phase-only liquid-crystal spatial light modulator for wave-front correction with high precision. Opt. Express 2004, 12, 6403-6409. [CrossRef] [PubMed]

13. Crossland, W.A.; Wilkinson, T.D.; Manolis, I.G.; Redmond, M.M.; Davey, A.B. Telecommunications applications of LCOS devices. Mol. Cryst. Liq. Cryst. 2002, 375, 1-13. [CrossRef]

14. Davis, S.R.; Sparks, A.W.; Fegely, L.; Gann, D.; Kemiao, J. Compact steering technologies for automotive lidar: A comparison between liquid crystal clad waveguides and optical mems. Appl. Lasers Sens. Free Space Commun. 2018, 3, STu2H-3.

15. Li, S.Q.; Xu, X.; Veetil, R.M.; Valuckas, V.; Paniagua-Domínguez, R.; Kuznetsov, A.I. Phase-only transmissive spatial light modulator based on tunable dielectric metasurface. Science 2019, 364, 1087-1090. [CrossRef]

16. Maimone, A.; Georgiou, A.; Kollin, J.S. Holographic near-eye displays for virtual and augmented reality. ACM Trans. Graph. 2017, 36, 85. [CrossRef]

17. Matsuda, N.; Fix, A.; Lanman, D. Focal surface displays. ACM Trans. Graph. 2017, 36, 86. [CrossRef]

18. Fan-Chiang, K.H.; Huang, S.H.; Shen, C.Y.; Wang, H.L.; Li, Y.W.; Tsai, H.C.; Huang, Y.P. Analog LCOS SLM devices for AR display applications. J. Soc. Inf. Disp. 2020, 28, 581-590. [CrossRef] 
19. Wu, S.T.; Lackner, A.M.; Efron, U. Optimal operation temperature of liquid crystal modulators. Appl. Opt. 1987, 26, 3441-3445. [CrossRef]

20. Lackner, A.M.; Margerum, J.D.; Miller, L.J.; Smith, W.H., Jr. Near ultraviolet photostability of liquid-crystal mixtures. Mol. Cryst. Liq. Cryst. 1986, 141, 289-310. [CrossRef]

21. Yakovenko, S.; Konovalov, V.; Brennesholtz, M. Lifetime of single panel LCOS imagers. SID Symp. Dig. Tech. Pap. $2004,35,64-67$. [CrossRef]

22. Janning, J.L. Thin film surface orientation for liquid crystals. Appl. Phys. Lett. 1972, 21, 173-174. [CrossRef]

23. Wen, C.H.; Gauza, S.; Wu, S.T. Photostability of liquid crystals and alignment layers. J. Soc. Inf. Disp. 2005, 13, 805-811. [CrossRef]

24. Yang, Q.; Zou, J.; Li, Y.; Wu, S.T. Fast-response liquid crystal phase modulators with an excellent photostability. Crystals 2020, 10, 765. [CrossRef]

25. Wu, S.T.; Wu, C.S. Rotational viscosity of nematic liquid crystals A critical examination of existing models. Liq. Cryst. 1990, 8, 171-182. [CrossRef]

26. Wu, S.T.; Efron, U.; Hess, L.D. Birefringence measurements of liquid crystals. Appl. Opt. 1984, 23, 3911-3915. [CrossRef]

27. $\mathrm{Wu}, \mathrm{S}$.T. Birefringence dispersions of liquid crystals. Phys. Rev. A 1986, 33, 1270-1274. [CrossRef]

28. Huang, Y.; He, Z.; Wu, S.T. Fast-response liquid crystal phase modulators for augmented reality displays. Opt. Express 2017, 25, 32757-32766. [CrossRef]

29. Chen, H.; Gou, F.; Wu, S.T. Submillisecond-response nematic liquid crystals for augmented reality displays. Opt. Mater. Express 2017, 7, 195-201. [CrossRef] 